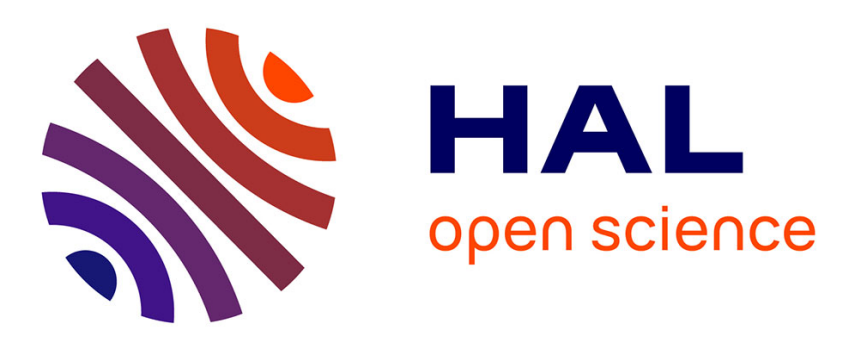

\title{
A dileucine signal situated in the C-terminal tail of the lysosomal membrane protein p40 is responsible for its targeting to lysosomes
}

Marielle Boonen, Roberta Rezende de Castro, Gaëlle Cuvelier, Isabelle Hamer, Michel Jadot

\section{To cite this version:}

Marielle Boonen, Roberta Rezende de Castro, Gaëlle Cuvelier, Isabelle Hamer, Michel Jadot. A dileucine signal situated in the C-terminal tail of the lysosomal membrane protein $\mathrm{p} 40$ is responsible for its targeting to lysosomes. Biochemical Journal, 2008, 414 (3), pp.431-440. 10.1042/BJ20071626 . hal-00478932

\section{HAL Id: hal-00478932 \\ https://hal.science/hal-00478932}

Submitted on 30 Apr 2010

HAL is a multi-disciplinary open access archive for the deposit and dissemination of scientific research documents, whether they are published or not. The documents may come from teaching and research institutions in France or abroad, or from public or private research centers.
L'archive ouverte pluridisciplinaire HAL, est destinée au dépôt et à la diffusion de documents scientifiques de niveau recherche, publiés ou non, émanant des établissements d'enseignement et de recherche français ou étrangers, des laboratoires publics ou privés. 


\section{A DILEUCine Signal SituATEd IN THE C-TERMinal TAIL OF THE LySOSOMAL MEMbRANE PROTEIN P40 IS RESPONSIBLE FOR ITS TARGETING TO LYSOSOMES}

Marielle BOONEN, Roberta REZENDE de CASTRO, Gaëlle CUVELIER, Isabelle HAMER, Michel JADOT

URФM, Laboratoire de Chimie Physiologique, FUNDP, B-5000 Namur, Belgium

Address correspondence to M. Jadot, UR $\Phi M$, Laboratoire de Chimie Physiologique, Facultés

Universitaires Notre-Dame de la Paix, 61, rue de Bruxelles, B-5000 Namur, Belgium

Tel. ++32 (0)81724262 ; Fax. ++32 (0)81724272 ; E-mail: michel.jadot@fundp.ac.be

Running Title: Lysosomal targeting of p40

Keywords: Lysosome, membrane, p40, dileucine signal, trafficking

\section{ABSTRACT}

Transport of newly synthesised lysosomal membrane proteins from the TGN to the lysosomes is due to the presence of specific signals in their cytoplasmic domains that are recognised by cytosolic adaptors. p40, a hypothetical transporter of 372 amino acids localised in the lysosomal membrane, contains four putative lysosomal sorting motifs in its sequence: three of the $\mathrm{YXX} \phi$-type $\left(\mathrm{Y}^{6} \mathrm{QLF}\right.$, $\left.\mathrm{Y}^{106} \mathrm{VAL}, \mathrm{Y}^{333} \mathrm{NGL}\right)$ and one of the $[\mathrm{D} / \mathrm{E}] \mathrm{XXXL}[\mathrm{L} / \mathrm{I}]$-type $\left(\mathrm{EQERL}{ }^{360} \mathrm{~L}^{361}\right)$. To test the implication of these motifs in the biosynthetic transport of p40, we replaced the most critical residues of these consensus sequences, the tyrosine or the leucine-leucine pair, by alanine or alanine-valine, respectively. We analysed the subcellular localisation of the mutated p40 proteins in transfected HeLa cells by confocal microscopy and by biochemical approaches (subcellular fractionation on selfforming Percoll density gradients and cell surface biotinylation). Our results show that p40 is mistargeted to the plasma membrane when its dileucine motif is disrupted. No role of the tyrosine motifs could be put forward. Taken together, our results provide evidence that the sorting of p40 from the TGN to the lysosomes is directed by the dileucine EQERL ${ }^{360} \mathrm{~L}^{361}$ motif situated in its C-terminal tail.

Abbreviations used: TGN, trans-Golgi Network; LAMP-1, Lysosome-associated membrane protein; LIMP-II, Lysosomal integral membrane protein; LAP, Lysosomal Acid Phosphatase; AP, Adaptor Protein; HA, Hemagglutinin; GFP, Green Fluorescent Protein; ER, Endoplasmic Reticulum; TRdextran, Texas Red-Dextran 


\section{INTRODUCTION}

The vesicular transport of newly synthesised lysosomal membrane proteins from the transGolgi network (TGN) to the lysosomes can follow two routes. The precursor proteins can either be sent directly toward the endo/lysosomal system, or be first targeted to the plasma membrane where they can be addressed to the lysosomes by endocytosis. The incorporation of the transmembrane proteins into coated budding vesicles destined to lysosomes is due to the presence of specific signals in their cytosolic domains. These signals are short amino acid sequences, generally of the YXX $\phi$-type (tyrosine-based signal) where $\phi$ is a bulky hydrophobic amino acid, or [D/E]XXXL[L/I]-type (dileucine-based signal) [1]. The tyrosine and the leucine-leucine (or leucine/isoleucine) residues are critical for the sorting step, their mutation severely impairing the targeting of the membrane proteins to lysosomes. These motifs are often situated within cytosolic regions, near the carboxy-terminal end of the transmembrane protein like in LAMP-1, LIMP-II or LAP [2-4], or near its amino-terminal end, like in sialin [5].

The recognition of the lysosomal sorting signals by cytosolic adaptor molecules allows the selection and the concentration of the membrane proteins into budding sites at the TGN or plasma membrane. The most extensively investigated adaptors are the heterotetrameric complexes AP-1, AP2 , AP-3 and AP-4, each of them composed by one small ( $\sigma 1-\sigma 4)$, one medium $(\mu 1-\mu 4)$ and two large subunits ( $\beta 1-\beta 4$ and $\gamma$ for AP-1, $\alpha$ for AP-2, $\delta$ for AP-3 or $\varepsilon$ for AP-4) $[6,7]$. It is well established that tyrosine-based motifs are recognised by the $\mu$ subunits [8]. By contrast, the binding site for dileucinebased motif is still controversial. It has been reported that this motif could bind to the $\beta$ subunits of AP-1 and AP-2 [9, 10] and the $\mu$ subunit of AP1, AP-2 and AP-3 [11-13]. More recent studies have revealed stronger interactions between the $[\mathrm{D} / \mathrm{E}] \mathrm{XXXL}[\mathrm{L} / \mathrm{I}]$ motif and specific combinations of two subunits from the AP-1 and AP-3 complexes ( $\gamma / \sigma 1$ and $\delta / \sigma 3$ hemicomplexes) [14] or from the AP-1 and AP-2 complexes ( $\gamma / \sigma 1$ and $\alpha / \sigma 2$ hemicomplexes) [15]. Mammalian AP-1 and AP-2 are mainly associated with the TGN and the plasma membrane, respectively, where they bind cargo molecules destined to the endosomal system and promote the vesicle coat assembly $[16,17]$. The presence of AP-1 is also observed at endosomal sites where it plays a role in the retrograde transport from endosomes to the TGN [18]. AP-3 is localised on endosomes and on the TGN, where it has been implicated in the sorting of lysosomal proteins [19-22], as well as in the biogenesis of "lysosomerelated" organelles such as melanosomes, some synaptic vesicles, secretion granules or platelet dense granules [23-27]. AP-4 has been mainly detected in clathrin-coated and -uncoated areas of the TGN, in endosomes and in transport vesicles [28, 29], and has been shown to play a role in a direct intracellular trafficking route to lysosomes and in the basolateral membrane sorting in MDCK cells [30,31].

The lysosomal membrane protein we are interested in, is a predicted multispanning protein of 372 amino acids named $\mathrm{p} 40$. This protein has been identified by mass spectrometry analysis of the most hydrophobic proteins extracted from a rat liver lysosomal membrane preparation [32]. Its association with the lysosomes has been previously validated by subcellular fractionation performed on mouse liver and by fluorescence microscopic examination, performed on transiently transfected cells [32]. p40 contains four putative lysosomal sorting motifs: $\mathrm{Y}^{6} \mathrm{QLF}, \mathrm{Y}^{106} \mathrm{VAL}, \mathrm{Y}^{333} \mathrm{NGL}$ and EQERL ${ }^{360} \mathrm{~L}^{361}$, respectively. To determine their potential role in the biosynthetic transport of $\mathrm{p} 40$ to the lysosomal membrane, we have disrupted each of these putative signals by site-directed mutagenesis. The critical tyrosine residues have been replaced by an alanine, and the two leucine residues (360-361) by an alanine and a valine. The impact of these mutations on the localisation of $\mathrm{p} 40$ has been analysed by confocal fluorescence microscopy and biochemically, using subcellular fractionation on selfforming Percoll density gradients and cell surface biotinylation. Our results demonstrate that the dileucine motif situated near the C-terminal end of p40 is an essential determinant for the targeting of this protein to the lysosomal membrane.

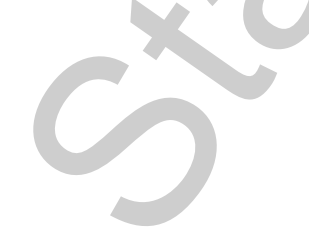




\section{MATERIAL AND METHODS}

\section{Mutation of the potential lysosomal targeting signals}

p40-GFP and GFP-p40 proteins were engineered as described in Boonen et al. [32]. Mutations of putative sorting motifs were introduced in wild-type p40-GFP by overlap extension using PCR. The tyrosine residues of the $\mathrm{Y}^{6} \mathrm{QLF}, \mathrm{Y}^{106} \mathrm{VAL}$ and $\mathrm{Y}^{333} \mathrm{NGL}$ motifs were replaced by alanine residues (Y6A, Y106A and Y333A), whereas the two leucine residues in the C-terminal EQERL ${ }^{360} \mathrm{~L}^{361}$ motif were substituted by an alanine and a valine, respectively (LL360AV). The primers (sense and antisense) bearing the mutations were the following: Y6A-F (5'-GT AAG GCC CAG TTG TTC CTG GCC G-3'); Y6A-R (5'-CAA CTG GGC CTT AGT CCA GGC CAT A-3'); Y106A-F (5'-C ATG $G C C$ GTG GCC CTG AAC ATG ACC A-3'); Y106A-R (5'-C CAC GGC CAT GAT GCT GGT CCC AGT C-3'); Y333A-F (5'-GCC CTC GCC AAT GGG CTG CAC CGA CCA CT-3'); Y333A-R (5'-CCC ATT GGC GAG GGC GGT GCC CAT AAG G-3'); LL360AV-F (5'-A GAG AGA GCG GTA GGT GAC AGT CGG ACT CCC-3') and LL360AV-R (5'-CT GTC ACC TAC CGC TCT CTC TTG CTC TCC C-3'). Final mutated PCR products were cloned into pCMV-Sport6_p40-GFP by EcoRI/BamHI.

To introduce the dileucine mutation into wild-type p40 (without GFP), a linker containing an EcoRI restriction site and a stop codon (5'-GATCCCTGAGAATTCTCAGG-3') was generated and inserted at the BamHI restriction site situated between p40 and the GFP in p40-LL360AV-GFP. The p40 fragment, bearing the dileucine mutation, was then excised by EcoRI and cloned in place of wild-type p40 in pCMV-Sport6_p40 to obtain pCMV-Sport6_p40-LL360AV. This construct was used to generate GFP-p40 bearing the dileucine substitution (LL360AV). The p40-LL360AV fragment was excised by BstEII and MluI and inserted into GFP-p40 via the same restriction enzymes.

An hemagglutinin (HA) tag was introduced at the C-terminal end of p40, by excision of the GFP moiety of p40-GFP with BamHI and NotI and its replacement by a linker containing the HA-tag, a stop codon, and BamHI/NotI restriction sites. The linker was formed by the hybridisation of the two following primers: 5'- GAT CCG TAC CCA TAC GAC GTC CCA GAC TAC GCT TGA T -3' and 5'- C TAG ATC AAG CGT AGT CTG GGA CGT CGT ATG GGT ACG -3'). The fusion of the HAtag at the $\mathrm{C}$-terminal end of the dileucine mutant of $\mathrm{p} 40$ was performed by replacing the wild-type $\mathrm{p} 40$ portion of p40-HA by the same dileucine mutated portion excised from p40-LL360AV-GFP. This was performed by enzymatic restriction with EcoRI and BamHI.

\section{Cell culture and transient transfection}

HeLa cells were cultured at $37^{\circ} \mathrm{C}$ in a humidified atmosphere with $5 \% \mathrm{CO}_{2}$ in glucose-rich Dulbecco's modified Eagle medium (DMEM) (LONZA, Verviers, Belgium) containing 10\% fetal calf serum (Greiner Bio-one), $100 \mathrm{U} / \mathrm{ml}$ penicillin and $100 \mu \mathrm{g} / \mathrm{ml}$ streptomycin. Transient transfections of plasmids were performed with the FuGene transfection reagent (Roche Diagnostics, Vilvoorde, Belgium) according to the manufacturer's instructions.

\section{Fluorescence labelling}

Forty-eight hours post-transfection with GFP contructs, HeLa cells were fixed with methanol/acetone (80:20) for $20 \mathrm{~min}$ at $-20^{\circ} \mathrm{C}$ and permeabilised with $0.05 \%$ saponin for $10 \mathrm{~min}$ at room temperature. After blocking of the non-specific binding sites for $10 \mathrm{~min}$ at room temperature with $1 \%$ BSA in PBS, cells were incubated for $2 \mathrm{~h}$ with a mouse anti-human LAMP-1 monoclonal antibody (H4A3, Developmental Studies of Hybridoma Bank, Iowa, IA, USA), followed by an Alexa 568-conjugated goat anti-mouse antibody (Molecular Probes, Invitrogen, Merelbeke, Belgium) for $50 \mathrm{~min}$. Coverslips were mounted in Mowiol and fluorescence was observed with a Leica ${ }^{\mathrm{TM}}$ confocal microscope.

Similar protocol was applied in cells transfected with $\mathrm{p} 40$ or p40-HA constructs, except that p40 proteins were detected with a specific polyclonal rabbit antibody directed against the last 15 amino acids of p40 (ERLLGDSRTPINEAS) or with an anti-HA polyclonal rabbit antibody (Sigma-Aldrich, Saint-Louis, MO, USA), respectively. Primary antibodies were detected with an Alexa 488-conjugated goat anti-rabbit antibody (Molecular Probes, Invitrogen, Merelbeke, Belgium). 
The labelling with Texas Red-dextran of HeLa cells transfected with p40-GFP constructs was performed as previously described [32]. Briefly, cells were incubated for $30 \mathrm{~min}$ in serum-free DMEM at $37^{\circ} \mathrm{C}$ and then for $6 \mathrm{~h}$ in DMEM with serum containing $2 \mathrm{mg} / \mathrm{ml}$ of Texas Red-dextran $(10,000$ MW, Molecular Probes, Invitrogen, Merelbeke, Belgium). After 4 washes with HBSS, cells were incubated for $2 \mathrm{~h}$ in dextran-free medium, washed again, fixed with ice-cold $4 \%$ paraformaldehyde and mounted in Mowiol (Calbiochem).

\section{Inhibition of AP-2-dependent endocytosis}

For the study on the intracellular trafficking of p40, HeLa cells were transiently co-transfected with either the wild-type or the dileucine mutated p40 tagged with the HA epitope along with a dominant negative construct of Eps15 (GFP-EA95/295) (kindly provided by Dr. A. Benmerah). Twenty-four hours post-transfection, cells were washed, fixed with $4 \%$ paraformaldehyde and permeabilised in $1 \%$ Triton X-100. The inhibition of the AP-2-dependent endocytosis was checked by incubating HeLa cells transiently transfected with the GFP-E $\Delta 95 / 295$ construct alone, during $15 \mathrm{~min}$ with $50 \mu \mathrm{g} / \mathrm{ml}$ of Alexa 568-conjugated human transferrin (Molecular Probes, Invitrogen, Merelbeke, Belgium). Cells were then washed three times in cold PBS and fixed in $4 \%$ paraformaldehyde. Blocking and labelling were processed as described above.

\section{Cell surface biotinylation}

Transfected HeLa cells were washed twice with ice-cold PBS and five times with PBS supplemented with $0.7 \mathrm{mM} \mathrm{CaCl}_{2}$ and $0.25 \mathrm{mM} \mathrm{MgSO}{ }_{4}\left(\mathrm{PBS}^{++}, \mathrm{pH}\right.$ 8), Cell surface proteins were labelled by incubation with $1 \mathrm{mg} / \mathrm{ml}$ of sulfo-NHS-SS-Biotin in $\mathrm{PBS}^{++}$(Pierce, Rockford, IL, USA) for $45 \mathrm{~min}$ on ice. Biotinylation was stopped by washing 5 times with ice-cold $50 \mathrm{mM}$ glycine/PBS ${ }^{++}$and cells were lysed with RIPA buffer (50 mM Tris- $\mathrm{HCl}, \mathrm{pH} 7.4,120 \mathrm{mM} \mathrm{NaCl}, 1 \%$ Triton X-100, 0.1\% SDS, $1 \%$ deoxycholate) containing protease inhibitors (Complete, Mini, Protease inhibitor cocktail tablets, Roche, Mannheim, Germany). Biotinylated proteins were precipitated with streptavidine-agarose beads (Pierce, Rockford, IL, USA) by centrifugation at $4^{\circ} \mathrm{C}$ for $5 \mathrm{~min}$ at $5,000 \mathrm{~g}$ in a bench top centrifuge and then eluted by incubation for $40 \mathrm{~min}$ at room temperature in Laemmli's buffer containing $200 \mathrm{mM}$ of fresh DTT. One tenth of the supernatant obtained after centrifugation, containing proteins unbound to streptavidine beads, and proteins eluted from the beads (bound) were loaded onto a $12 \%$ SDS-PAGE. Proteins were electrotransferred onto low fluorescence PVDF membranes (Amersham Hybond LFP, GE Healthcare, Buckinghamshire, United Kingdom) which were blocked for 10 min with $10 \%$ skimmed milk in $0.1 \%$ Tween/PBS. Detection of p40, p40-HA or GFP-tagged proteins was performed with a rabbit antiserum raised against the $15 \mathrm{C}$-terminal amino acids of mouse p40, with a rabbit polyclonal antibody anti-HA (Sigma, Saint-Louis, MO, USA) or with a rabbit polyclonal antibody directed against GFP (Santa Cruz Biotechnology, Huissen, Netherlands), respectively. Membranes were then incubated for $1 \mathrm{~h}$ with an Alexa 488-conjugated goat anti-rabbit antibody (Molecular Probes, Invitrogen, Merelbeke, Belgium). Signal detection was performed using the Typhoon ${ }^{\mathrm{TM}}$ fluorescence scanning system (GE Healthcare, Buckinghamshire, United Kingdom) and intensities were quantified with the ImageQuant ${ }^{\mathrm{TM}}$ analysis software (GE Healthcare, Buckinghamshire, United Kingdom).

\section{Self-forming Percoll density gradient}

Confluent cells grown in three 100-mm Petri dishes were rinsed three times with PBS, then twice with ice-cold $0.25 \mathrm{M}$ sucrose. Cells were scraped in $1 \mathrm{~mL}$ of ice-cold $0.25 \mathrm{M}$ sucrose and homogenised by 10 passages through a 25-gauge needle mounted on a $5 \mathrm{ml}$ syringe. Cell homogenate was subjected to a centrifugation at $1,500 \mathrm{rpm}$ for $10 \mathrm{~min}$ at $4^{\circ} \mathrm{C}$ in an International Centrifuge PR-J (International Equipment Co.). The pellet was suspended in $2 \mathrm{ml}$ of ice-cold $0.25 \mathrm{M}$ sucrose, disrupted by 10 passages through a 25-gauge needle and submitted to another centrifugation at 1,500 rpm for $10 \mathrm{~min}$ at $4^{\circ} \mathrm{C}$. This second pellet corresponded to the nuclear fraction $(\mathrm{N})$. The $4-5 \mathrm{~mL}$ post-nuclear supernatant was then centrifuged at $35,000 \mathrm{rpm}$ for $40 \mathrm{~min}$ in a Beckman 50Ti rotor $\left(4^{\circ} \mathrm{C}\right)$ in order to sediment the membrane compartments (MLP fraction). The MLP pellet was resuspended in $1 \mathrm{~mL}$ of ice-cold 
sucrose and mixed with $8 \mathrm{ml}$ of an $18 \%$ Percoll solution (18\% v/v Percoll, $0.25 \mathrm{M}$ sucrose, $2 \mathrm{mM}$ EDTA, $10 \mathrm{mM}$ Tris-HCl, pH 7.4). The solution $(9 \mathrm{ml})$ was then layered onto $1 \mathrm{ml}$ of a $2.2 \mathrm{M}$ sucrose cushion and centrifuged for $1 \mathrm{~h}$ at $20,000 \mathrm{~g}_{\mathrm{av}}$ in a Beckman 50Ti rotor at $4^{\circ} \mathrm{C}$. Seven fractions were collected from the top to the bottom of the gradient. The $\beta$-galactosidase and alkaline phosphodiesterase enzymatic activities were assayed in each fraction as described previously [33, 34]. The distributions of the p40/p40-GFP and LAMP-1 proteins were analysed by Western blotting as described above, except that the signals detection was performed using the Western Lightning Chemiluminescence Reagent Plus (Perkin Elmer Life Science, Zaventem, Belgium). 


\section{RESULTS}

\section{Mutation of the putative lysosomal sorting motifs of p40: effect on its localisation in transfected cells}

p40 contains four putative lysosomal sorting motifs: three of the tyrosine-type ( $\mathrm{Y}^{6} \mathrm{QLF}$, $\mathrm{Y}^{106} \mathrm{VAL}$ and $\mathrm{Y}^{333} \mathrm{NGL}$ ), and one of the dileucine-type (EQERL ${ }^{360} \mathrm{~L}^{361}$ ) (Figure 1). Based on computational topology prediction models, it seems unlikely that the tyrosine motif at position 106 acts as a sorting signal since it appears to be localised in one of the 8-10 predicted transmembrane regions. Nevertheless, we analysed the role of each motif in the biosynthetic transport of $\mathrm{p} 40$ to lysosomes. We first engineered a GFP chimaeric protein in which the GFP was fused C-terminally to the mouse p40 protein (p40-GFP). Then, we mutated each putative signal separately in the p40-GFP protein. We replaced the critical tyrosine residues by alanine (mutations Y6A, Y106A or Y333A) and the two leucine residues of the EQERL ${ }^{360} \mathrm{~L}^{361}$ sequence by an alanine and a valine, respectively (mutation LL360AV) (Figure 1). The wild-type and mutated p40-GFP proteins were transfected in HeLa cells and their subcellular localisation was observed $48 \mathrm{~h}$ post-transfection by confocal fluorescence microscopy. The late endosomal/lysosomal compartments were localised by immunofluorescence, using an antibody directed against LAMP-1 (Figure 2A). As previously shown [32], wild-type p40-GFP transfected in HeLa cells displayed a punctuated labelling throughout the cytoplasm with a predominance in the perinuclear region, and extensively colocalised with LAMP-1 (Figure 2A). No signal was detected at the plasma membrane. A similar distribution was observed for p40 (without the GFP-tag), and for p40 proteins with a GFP-tag fused N-terminally (GFP-p40) or a HA-tag fused C-terminally (p40-HA) (Figure 2A). These results suggest that the addition of a GFP or a HA-tag does not interfere with the lysosomal localisation of the protein.

The p40-GFP proteins mutated at one tyrosine motif (Y6A, Y106A or Y333A) exhibited the same distribution as that of wild-type p40-GFP, and thus extensively colocalised with LAMP-1 (Figure 2B). In contrast, substitution of the two leucine residues of the C-terminal EQERL ${ }^{360} \mathrm{~L}^{361}$ motif induced the targeting of p40-GFP proteins to the plasma membrane (Figure 3A). Similar results were obtained after the introduction of the dileucine mutation in wild-type p40, in GFP-p40 or in p40-HA chimaeric proteins (Figure 3A). The partial diversion of the p40 dileucine mutant to the cell surface was also observed after transfection in BHK21 cells (Figure 1S, Supplementary data). Nevertheless, irrespective of the construct, a significant portion of the LL360AV mutated proteins still generated an intracellular signal and colocalised with LAMP-1 both in HeLa cells and BHK21 cells (Figures 3A and $1 \mathrm{~S}$ ).

Cells transfected with p40-GFP or its dileucine mutated form were incubated with Texas Red-dextran (Figure 3B). This molecule enters the cells by fluid-phase endocytosis and is transported through the early and late endosomes to the lysosomes where it accumulates owing to its resistance to hydrolysis. Incubation of the transfected cells with Texas Red-dextran for $6 \mathrm{~h}$ followed by a $2 \mathrm{~h}$-chase in dextranfree medium to allow its accumulation in late endocytic compartments, revealed an extensive colocalisation between the fluorescent probe and wild-type p40-GFP (Figure 3B). The intracellular signal observed for the dileucine mutant of p40-GFP also extensively colocalised with the fluorescent probe (Figure 3B), confirming its partial localisation in a compartment of the endocytic pathway.

The observation of a dual intracellular/plasma membrane localisation for the dileucine mutant raises the possibility of another functional sorting determinant which could mediate the targeting of p40 to lysosomes in the absence of the EQERL ${ }^{360} \mathrm{~L}^{361}$ motif. In order to test the putative contribution of the tyrosine motifs to the sorting of p40 when the dileucine signal is disrupted, these motifs were mutated in the LL360AV-mutated p40-GFP construct. All p40-GFP proteins bearing the LL360AV substitution, in addition to the mutation of one tyrosine motif (double mutants) or the three tyrosine motifs together (quadruple mutant), were partly associated with the plasma membrane (Figure 4). However, as observed with the single dileucine mutated proteins, a subpopulation of each mutant protein remained associated with a LAMP-1 positive intracellular compartment (Figure 4), suggesting that the tyrosine mutations had no additional effect on the mistargeting of $\mathrm{p} 40$ proteins to the plasma membrane, compared to the single LL360AV mutation. 


\section{Distribution of wild-type and mutated p40 proteins (LL360AV) on Percoll density gradients}

We tested the delivery of wild-type p40 and p40-GFP, with and without the LL360AV substitution, to dense lysosomes as identified by centrifugation on a self-forming Percoll density gradient. MLP fractions (the high speed pellets of post-nuclear supernatants) were submitted to centrifugation on iso-osmotic self-forming Percoll density gradients. Measurements of $\beta$-galactosidase and alkaline phosphodiesterase activities were performed in the collected fractions, in order to localise the lysosomes and the plasma membrane, respectively. As expected, the majority of the $\beta$ galactosidase activity was recovered in the highest density fractions, while the plasma membrane marker was mainly associated with more buoyant fractions (Figure 5). Detection of $\mathrm{p} 40$ and p40-GFP proteins by Western blotting revealed their presence in all fractions with a predominance in the light density fractions $(\sim 1.052-1.057 \mathrm{~g} / \mathrm{mL})$ and in the highest density fraction $(\sim 1.16 \mathrm{~g} / \mathrm{mL})$. This pattern was similar to the bimodal distribution profile of the late endosomal/lysosomal marker LAMP-1. By contrast, the dileucine mutants (LL360AV) with and without GFP, were not detected in the dense lysosomes containing fractions. This shift in p40 distribution observed on Percoll density gradients after substitutions of the two leucine residues at positions 360-361, confirms the crucial role of the dileucine motif in the targeting of p40 to lysosomes.

\section{Plasma membrane association of the wild-type and mutated p40 proteins}

The relative abundance of the wild-type and mutated proteins at the plasma membrane was estimated by cell surface biotinylation. Transfected cells were incubated with sulfo-NHS-SS-Biotin for $45 \mathrm{~min}$ on ice, lysed and incubated with streptavidine-agarose beads in order to separate the biotinylated (Bound) from the non-biotinylated (Unbound) proteins. The bound proteins, eluted from the beads, and one tenth of the unbound proteins were resolved by SDS-PAGE. The proportion of each p40 construct recovered in the Bound and Unbound samples was estimated by Western blotting using the fluorescence based ECL Plex ${ }^{\mathrm{TM}}$ system (GE Healthcare, Buckinghamshire, UK). Detection of the intracellular EEA1 (Early Endosome Antigen 1) protein was used as a control of membrane integrity. As shown in figure 6A, wild-type p40-GFP and the corresponding proteins mutated in one of the tyrosine motif (Y6A, Y106A or Y333A) were very poorly biotinylated $(<5 \%)$, supporting their intracellular localisation. The mutation of the dileucine signal (LL360AV) in p40-GFP induced the appearance of $21 \pm 3 \%(\mathrm{n}=6)$ of the molecules in the biotinylated fraction attesting of their exposure to the extracellular medium. Mutation of the tyrosine motifs at positions 6, 106, or 333, together with the dileucine signal (double and quadruple mutants) did not increase the percentage of proteins associated with the bound fraction, providing further evidence that the tyrosine motif mutations have little or no additional impact on the mistargeting of the dileucine mutant to the plasma membrane.

Wild-type p40, the C-terminally HA- and N-terminally GFP- tagged p40 constructs yielded very low percentages of proteins in their biotinylated form $(7 \pm 2 \%, 2 \pm 0 \%$ and $3 \pm 1 \%$, respectively, with $\mathrm{n} \geq 3$ ) (Figure 6B). When the dileucine mutation was introduced in p40-HA and GFP-p40, $24 \pm$ $4 \%(n=3)$ and $22 \pm 7 \%(n=3)$ of $p 40$ proteins were detected among the biotinylated proteins, respectively (Figure 6B), which was not different from the values obtained with the mutated p40-GFP protein $(21 \pm 3 \%$; $n=6)$ (Figure $6 \mathrm{~A})$. By contrast, in the absence of any tag, $49 \pm 11 \%(\mathrm{n}=7)$ of dileucine mutants were biotinylated (Figure 6B), showing that the presence of a GFP or a HA-tag has an effect on the association of the mutated protein with the cell surface.

\section{Intracellular trafficking of the wild-type and mutated p40 proteins}

In steady-state, only a low level of wild-type-p40 appears at the cell surface. We asked whether p 40 molecules passed through the plasma membrane on their way to the endolysosomal compartments, as described for other lysosomal membrane proteins, including the LAMPs [35]. To achieve this goal, we overexpressed p40 in HeLa cells together with a dominant negative form of Eps15, which is known to inhibit AP2-dependent endocytosis by sequestering AP-2 in the cytosol [36]. First, we checked the efficiency of this EH-deleted form of Eps15 tagged with GFP, to block AP2-dependent endocytosis by measuring the uptake of an Alexa 568-conjugated transferrin, a well 
known marker of clathrin-mediated endocytosis $[36,37]$. We observed that the uptake of transferrin was effectively inhibited although to very different extents in individual cells. The most prominent inhibition of transferrin uptake was observed in cells expressing a high level of GFP-Eps15 E $\triangle 95 / 295$ (Figure 7A). Then, we analysed the distribution of wild-type p40 in cotransfected cells expressing high levels of GFP-Eps15 E $\Delta 95 / 295$. As shown in Figure 7, the immunofluorescent staining of p40 remained in the perinuclear area as in cells expressing p40 alone (Figure 2A), and did never appear at the cell surface (Figure 7B). This result supports the idea that wild-type-p40 proteins gain access to the endolysosomal compartment without passing through the plasma membrane. The same experiment was carried out with the dileucine mutated p40 proteins and showed that the staining was present in an intracellular compartment but also at the cell surface (Figure 7C), as described above for the cells not transfected with the dominant negative form of Eps15. 


\section{DISCUSSION}

Our study on the implication of the four putative lysosomal sorting motifs of $\mathrm{p} 40$ ( $\mathrm{Y}^{6} \mathrm{QLF}$, $\left.\mathrm{Y}^{106} \mathrm{VAL}, \mathrm{Y}^{333} \mathrm{NGL}, \mathrm{EQERL}{ }^{360} \mathrm{~L}^{361}\right)$ in its biosynthetic transport to the lysosomes has revealed a key role of the C-terminal EQERL ${ }^{360} \mathrm{~L}^{361}$ motif. Indeed, replacement of the leucine pair by other amino acids (LL360AV) induced a mistargeting of the protein to the plasma membrane, as judged by confocal fluorescence microscopy and by cell surface biotinylation. Using this method, it appeared that, in steady-state, up to $49 \%$ of the untagged dileucine mutants were detected at the cell surface. Considering that a significant portion of dileucine mutated p40 proteins still colocalised with LAMP-1 and with the fluid-phase endocytosis tracer Texas Red-dextran after a $2 \mathrm{~h}$-chase period, we searched for another functional sorting signal in 40 sequence which could act in combination with the dileucine motif at the same or another step in the p40 transport towards lysosomes. With this in mind, we mutated the other putative targeting motifs found in $\mathrm{p} 40\left(\mathrm{Y}^{6} \mathrm{QLF}, \mathrm{Y}^{106} \mathrm{VAL}, \mathrm{Y}^{333} \mathrm{NGL}\right)$ together with the dileucine signal mutation. No additional impact on the mis-targeting of $\mathrm{p} 40$ to the plasma membrane was observed as compared to the single dileucine mutant, suggesting that the tyrosine motifs would not be implicated in p40 targeting to lysosomes. In the case of LAMP-1, it was shown that $95 \%$ of newly-synthesised LAMP-1 proteins mutated in their tyrosine-based sorting signal were expressed at the cell surface within 30 min after pulse labelling, suggesting that the tyrosine motif was the only lysosomal sorting signal, despite the presence of only $39 \%$ of tyrosine-mutated proteins at the cell surface in steady-state [38]. For practical reasons, probably linked to the hydrophobic nature of $\mathrm{p} 40$, we failed to determine the percentage of newly synthesised $\mathrm{p} 40$ expressed at the cell surface. However, our results clearly demonstrate that, unlike the tyrosine motifs, the EQERL ${ }^{360} \mathrm{~L}^{361}$ motif plays a crucial role in the lysosomal sorting of p40. In the future, it should be worthwhile to evaluate whether some of the numerous transmembrane domains of p40 contribute or not to its targeting and delivery to lysosomes, as it has been described for several integral membrane proteins $[39,40]$. The lower percentage of the GFP- and HA-tagged mutated p40 proteins at the plasma membrane (21-24 $\%$ ) could be the consequence of a less efficient biosynthetic transport. Alternatively, the possible misfolding of the dileucine mutants fused to HA or GFP tags could trigger their ubiquitinylation and their sorting from the TGN or from the plasma membrane to the endosomal compartments [41-42]. This process could result in a lower cell surface to intracellular ratio as compared to untagged proteins.

Membrane proteins can be targeted to the endo/lysosomes either directly from the TGN or indirectly, passing first by the plasma membrane before being directed toward lysosomes along the endocytic pathway. The biosynthetic transport of the lysosomal acid phosphatase (LAP) provides an example of indirect traffic. Indeed, its precursor cycles several times between early endosomes and the plasma membrane before reaching lysosomes [43]. Trafficking through a direct pathway has been described for lysosomal membrane proteins such as LIMP-II, GLUT-8, mucolipin 1 and LAMP-1 [20, $38,44-48]$. Nevertheless, it has recently been suggested that a significant portion of LAMP-1 and GLUT-8 is also transported by an indirect pathway since the knock-down of the plasma membrane adaptor AP-2 in HeLa cells by siRNA has led to a substantial accumulation of these proteins at the cell surface $[10,35]$. In contrast, the sorting of mucolipin 1 and LIMP-II to lysosomes has been attributed to AP-1 or AP-1 and AP-3, respectively, supporting the idea of their trafficking by an intracellular (direct) route $[20,46,47]$. Our data lend support to a direct transport of wild-type p40 from the TGN to the lysosomes. Indeed, the coexpression of wild-type p40-HA and a dominant negative form of Eps15, known to inhibit clathrin-mediated endocytosis by interacting with AP-2 [36], did not result in the appearance of a detectable amount of 440 proteins at the plasma membrane. Therefore, it seems likely that newly-synthesised wild-type p 40 molecules reach the endosomal compartment primarily by the direct pathway following the interactions of the dileucine motif with either AP-1 or AP-3-adaptor complexes. The GEQERLL sequence from 440 can potentially be recognized by each of them by interactions with isolated subunits [9-13] but most likely with $\gamma / \sigma 1$ or $\delta / \sigma 3$ hemicomplexes [14, 15]. However, it does not fulfil the criteria described for optimal recognition by AP-3, i.e. the presence of a proline residue at position -1 , a positively charged amino acid at position -3 and acidic residues at positions -4 and -5 from the first leucine [49]. Nevertheless, like p40, the yeast acid lysosomal phosphatase which is known to interact with AP-3, contains an arginine residue at position -1 [1, 49]. In addition, it seems that the proline residue of ERAPLI motif from LIMP-II is dispensable for the 
interaction with the $\delta-\sigma 3 \mathrm{~A}$, and $\delta-\sigma 3 \mathrm{~B}$ hemicomplexes [14]. Therefore, both AP complexes could $a$ priori recognize the dileucine motif of $\mathrm{p} 40$.

The observation of a dual localisation of p40-LL360AV at the cell surface and intracellularly, where it co-localises with LAMP-1 could give rise to several interpretations. Part of the intracellular signal could represent molecules transiting along with LAMP-1 in biosynthetic compartments. Nevertheless, the extensive co-localisation of the dileucine mutant with endocytosed Texas reddextran after a $2 \mathrm{~h}$-chase seems rather to indicate that the bulk of the mutated proteins present inside the cells resides in organelles of the endocytic pathway. The presence of p40-LL360AV in late endosomal compartments could be the consequence of its impaired binding to AP- 1 and/or AP-3 adaptor complexes at the TGN, resulting in its diversion to the plasma membrane by default $[1,20,46$, 49-51]. Once at the cell surface, due to the absence of a functional dileucine motif, p40-LL360AV would be slowly internalised by a clathrin-dependent or independent pathway $[37,38,50]$. On the other hand, taking into account the partial localisation of the dileucine mutant in endolysosomal structures, and its exclusion from dense lysosomes as shown on Percoll density gradients, we cannot rule out the possibility that the dileucine signal would be involved in trafficking of the protein from late endosomes to dense lysosomes. It is commonly admitted that transport between these compartments occurs by default pathway but the existence of a signal-mediated pathway has already been proposed to explain the accumulation of a mutant form of LAMP-1 in a prelysosomal compartment [52]. Finally, we cannot rule out the possibility that the p40 dileucine mutant was not detected in the densest fractions of the Percoll gradient because it is more prone to lysosomal degradation than the wild-type $\mathrm{p} 40$. Disruption of the different AP complexes by specific siRNA would be required to clarify the intracellular trafficking of p40-LL360AV.

As previously mentioned, the elevated number of predicted transmembrane domains of $\mathrm{p} 40$ and the similarity of part of its sequence with Golgi nucleotide-sugar transporters raise the issue of a putative transport activity of p40 in the lysosomal membrane [32]. Small molecular weight molecules produced by the intralysosomal hydrolysis are transferred from the lumen of the organelle to the cytosol by membrane transporters. To date, only few transporters have been identified in lysosomes although transport activities have been described or suggested for a large number of molecules [5356]. Among the most extensively characterised lysosomal transporters are those in charge of the translocation of cystine (cystinosin) and of sialic acid (sialin), whose deficiency leads to lysosomal storage disorders [57-59]. The discovery of the sorting determinants of these membrane proteins has been of particular interest in the study of their transport activities. Indeed, expression of sialin and cystinosin at the plasma membrane, induced by the mutations of their sorting signals, has permitted the design of efficient transport assays [5, 60]. The results of our study, demonstrating the role of the p40 EQERL ${ }^{360} \mathrm{~L}^{361}$ sequence in its biosynthetic routing could therefore represent a valuable step toward the implementation of similar methods in an attempt to unravel the function of this protein.

Acknowledgements. We thank Dr. C. Lambert de Rouvroit, (URФM, FUNDP, Namur, Belgium), Dr. B. Gasnier and Dr. C. Sagné (Laboratoire de biologie cellulaire et moléculaire de la sécrétion, IBPC, Paris, France) for helpful suggestions. We acknowledge Dr. A. Benmerah (Department of infectious diseases, Institut Cochin, Paris) for the kind gift of the mutant constructs of Eps15. We also thank D. Desnoeck and C. Demazy for their technical assistance (UR $\Phi M$ and URBC, FUNDP, Namur, Belgium). This work was supported by the Fonds de la Recherche Fondamentale Collective (Contract $\mathrm{n}^{\circ}$ 2.4505.01). M. Boonen is the recipient of a fellowship from the "Fonds pour la formation à la Recherche dans l'Industrie et l'Agriculture (FRIA)". 


\section{REFERENCES}

1 Bonifacino, J. S. and Traub, L. M. (2003) Signals for Sorting of Transmembrane Proteins to Endosomes and Lysosomes. Annu. Rev. Biochem. 72, 395-447

2 Obermuller, S., Kiecke, C., von Figura, K. and Honing, S. (2002) The tyrosine motifs of Lamp 1 and LAP determine their direct and indirect targetting to lysosomes. J. Cell. Sci. 115, 185-194

3 Sandoval, I. V., Arredondo, J. J., Alcalde, J., Gonzalez Noriega, A., Vandekerckhove, J., Jimenez, M. A. and Rico, M. (1994) The residues Leu(Ile)475-Ile(Leu, Val, Ala)476, contained in the extended carboxyl cytoplasmic tail, are critical for targeting of the resident lysosomal membrane protein LIMP II to lysosomes. J. Biol. Chem. 269, 6622-6631

4 Williams, M. A. and Fukuda, M. (1990) Accumulation of membrane glycoproteins in lysosomes requires a tyrosine residue at a particular position in the cytoplasmic tail. J. Cell Biol. 111, 955-966

5 Morin, P., Sagne, C. and Gasnier, B. (2004) Functional characterization of wild-type and mutant human sialin. EMBO J. 23, 4560-4570

6 Edeling, M. A., Smith, C. and Owen, D. (2006) Life of a clathrin coat: insights from clathrin and AP structures. Nat. Rev. Mol. Cell. Biol. 7, 32-44

7 Hirst, J. and Robinson, M. S. (1998) Clathrin and adaptors. Biochim Biophys Acta. 1404, 173 193

8 Ohno, H., Stewart, J., Fournier, M. C., Bosshart, H., Rhee, I., Miyatake, S., Saito, T., Gallusser, A., Kirchhausen, T. and Bonifacino, J. S. (1995) Interaction of tyrosine-based sorting signals with clathrin-associated proteins. Science. 269, 1872-1875

9 Rapoport, I., Chen, Y. C., Cupers, P., Shoelson, S. E. and Kirchhausen, T. (1998) Dileucinebased sorting signals bind to the beta chain of AP-1 at a site distinct and regulated differently from the tyrosine-based motif-binding site. EMBO J. 17, 2148-2155

10 Schmidt, U., Briese, S., Leicht, K., Schurmann, A., Joost, H. G. and Al-Hasani, H. (2006) Endocytosis of the glucose transporter GLUT8 is mediated by interaction of a dileucine motif with the beta2-adaptin subunit of the AP-2 adaptor complex. J. Cell Sci. 119, 2321-2331

11 Craig, H. M., Reddy, T. R., Riggs, N. L., Dao, P. P. and Guatelli, J. C. (2000) Interactions of HIV-1 nef with the mu subunits of adaptor protein complexes 1, 2, and 3: role of the dileucine-based sorting motif. Virology. 271, 9-17

12 Hofmann, M. W., Honing, S., Rodionov, D., Dobberstein, B., von Figura, K. and Bakke, O. (1999) The leucine-based sorting motifs in the cytoplasmic domain of the invariant chain are recognized by the clathrin adaptors AP1 and AP2 and their medium chains. J. Biol. Chem. 274, 36153-36158

13 Rodionov, D. G. and Bakke, O. (1998) Medium chains of adaptor complexes AP-1 and AP-2 recognize leucine-based sorting signals from the invariant chain. J. Biol. Chem. 273, 6005-6008

14 Janvier, K., Kato, Y., Boehm, M., Rose, J. R., Martina, J. A., Kim, B. Y., Venkatesan, S. and Bonifacino, J. S. (2003) Recognition of dileucine-based sorting signals from HIV-1 Nef and LIMP-II by the AP-1 gamma-sigma1 and AP-3 delta-sigma3 hemicomplexes. J. Cell Biol. 163, 1281-1290

15 Doray, B., Lee, I., Knisely, J., Bu, G. and Kornfeld, S. (2007) The gamma/sigma1 and alpha/sigma2 hemicomplexes of clathrin adaptors AP-1 and AP-2 harbor the dileucine recognition site. Mol. Biol. Cell. 18, 1887-1896

16 Ahle, S., Mann, A., Eichelsbacher, U. and Ungewickell, E. (1988) Structural relationships between clathrin assembly proteins from the Golgi and the plasma membrane. EMBO J. 7, 919-929

17 Robinson, M. S. and Pearse, B. M. (1986) Immunofluorescent localization of 100K coated vesicle proteins. J. Cell Biol. 102, 48-54

18 Meyer, C, Zizioli, D., Lausmann, S., Eskelinen, E. L., Hamann, J., Saftig, P., von Figura, K. and Schu, P. (2000) mu1A-adaptin-deficient mice: lethality, loss of AP-1 binding and rerouting of mannose 6-phosphate receptors. EMBO J. 19, 2193-2203

19 Dell'Angelica, E. C., Ohno, H., Ooi, C. E., Rabinovich, E., Roche, K. W. and Bonifacino, J. S. (1997) AP-3: an adaptor-like protein complex with ubiquitous expression. EMBO J. 16, 917-928

20 Le Borgne, R., Alconada, A., Bauer, U. and Hoflack, B. (1998) The mammalian AP-3 adaptor-like complex mediates the intracellular transport of lysosomal membrane glycoproteins. J. Biol. Chem. 273, 29451-29461 
21 Peden, A. A., Oorschot, V., Hesser, B. A., Austin, C. D., Scheller, R. H. and Klumperman, J. (2004) Localization of the AP-3 adaptor complex defines a novel endosomal exit site for lysosomal membrane proteins. J. Cell Biol. 164, 1065-1076

22 Simpson, F., Peden, A. A., Christopoulou, L. and Robinson, M. S. (1997) Characterization of the adaptor-related protein complex, AP-3. J. Cell Biol. 137, 835-845

23 Daugherty, B. L., Straley, K. S., Sanders, J. M., Phillips, J. W., Disdier, M., McEver, R. P. and Green, S. A. (2001) AP-3 adaptor functions in targeting P-selectin to secretory granules in endothelial cells. Traffic. 2, 406-413

24 Dell'Angelica, E. C., Shotelersuk, V., Aguilar, R. C., Gahl, W. A. and Bonifacino, J. S. (1999) Altered trafficking of lysosomal proteins in Hermansky-Pudlak syndrome due to mutations in the beta 3A subunit of the AP-3 adaptor. Mol. Cell. 3, 11-21

25 Huizing, M., Sarangarajan, R., Strovel, E., Zhao, Y., Gahl, W. A. and Boissy, R. E. (2001) AP-3 mediates tyrosinase but not TRP-1 trafficking in human melanocytes. Mol. Biol. Cell. 12, 20752085

26 Salazar, G., Love, R., Werner, E., Doucette, M. M., Cheng, S., Levey, A. and Faundez, V. (2004) The zinc transporter ZnT3 interacts with AP-3 and it is preferentially targeted to a distinct synaptic vesicle subpopulation. Mol. Biol. Cell. 15, 575-587

27 Starcevic, M., Nazarian, R. and Dell'Angelica, E. C. (2002) The molecular machinery for the biogenesis of lysosome-related organelles: lessons from Hermansky-Pudlak syndrome. Sem Cell Dev Biol. 13, 271-278

28 Dell'Angelica, E. C., Mullins, C. and Bonifacino, J. S. (1999) AP-4, a novel protein complex related to clathrin adaptors. J. Biol. Chem. 274, 7278-7285

29 Hirst, J., Bright, N. A., Rous, B. and Robinson, M. S. (1999) Characterization of a fourth adaptor-related protein complex. Mol. Biol. Cell. 10, 2787-2802

30 Aguilar, R. C., Boehm, M., Gorshkova, I., Crouch, R. J., Tomita, K., Saito, T., Ohno, H. and Bonifacino, J. S. (2001) Signal-binding specificity of the mu4 subunit of the adaptor protein complex AP-4. J. Biol. Chem. 276, 13145-13152

31 Simmen, T., Honing, S., Icking, A., Tikkanen, R. and Hunziker, W. (2002) AP-4 binds basolateral signals and participates in basolateral sorting in epithelial MDCK cells. Nat. Cell Biol. 4, 154-159

32 Boonen, M., Hamer, I., Boussac, M., Delsaute, A. F., Flamion, B., Garin, J. and Jadot, M. (2006) Intracellular localization of $\mathrm{p} 40$, a protein identified in a preparation of lysosomal membranes. Biochem. J. 395, 39-47

33 Beaufay, H., Amar-Costesec, A., Thines-Sempoux, D., Wibo, M., Robbi, M. and Berthet, J. (1974) Analytical study of microsomes and isolated subcellular membranes from rat liver. 3. Subfractionation of the microsomal fraction by isopycnic and differential centrifugation in density gradients. J. Cell Biol. 61, 213-231

34 Peters, T. J., Muller, M. and De Duve, C. (1972) Lysosomes of the arterial wall. I. Isolation and subcellular fractionation of cells from normal rabbit aorta. J. Exp. Med. 136, 1117-1139

35 Janvier, K. and Bonifacino, J. S. (2005) Role of the endocytic machinery in the sorting of lysosome-associated membrane proteins. Mol. Biol. Cell. 16, 4231-4242

36 Benmerah, A., Bayrou, M., Cerf-Bensussan, N. and Dautry-Varsat, A. (1999) Inhibition of clathrin-coated pit assembly by an Eps15 mutant. J. Cell Sci. 112 ( Pt 9), 1303-1311

37 Motley, A., Bright, N. A., Seaman, M. N. and Robinson, M. S. (2003) Clathrin-mediated endocytosis in AP-2-depleted cells. J. Cell Biol. 162, 909-918

38 Harter, C. and Mellman, I. (1992) Transport of the lysosomal membrane glycoprotein lgp120 (lgp-A) to lysosomes does not require appearance on the plasma membrane. J Cell Biol. 117, 311-325

39 Reaves, B. J., Banting, G. and Luzio, J. P. (1998) Lumenal and transmembrane domains play a role in sorting type I membrane proteins on endocytic pathways. Mol. Biol. Cell. 9, 1107-1122

40 Scott, C., Higgins, M. E., Davies, J. P. and Ioannou, Y. A. (2004) Targeting of NPC1 to late endosomes involves multiple signals, including one residing within the putative sterol-sensing domain. J. Biol. Chem. 279, 48214-48223

41 Puertollano, R. and Bonifacino, J. S. (2004) Interactions of GGA3 with the ubiquitin sorting machinery. Nat. Cell Biol. 6, 244-251 
42 Sharma, M., Pampinella, F., Nemes, C., Benharouga, M., So, J., Du, K., Bache, K. G., Papsin, B., Zerangue, N., Stenmark, H. and Lukacs, G. L. (2004) Misfolding diverts CFTR from recycling to degradation: quality control at early endosomes. J. Cell Biol. 164, 923-933

43 Braun, M., Waheed, A. and von Figura, K. (1989) Lysosomal acid phosphatase is transported to lysosomes via the cell surface. EMBO J. 8, 3633-3640

44 Augustin, R., Riley, J. and Moley, K. H. (2005) GLUT8 contains a [DE]XXXL[LI] sorting motif and localizes to a late endosomal/lysosomal compartment. Traffic. 6, 1196-1212

45 Barriocanal, J. G., Bonifacino, J. S., Yuan, L. and Sandoval, I. V. (1986) Biosynthesis, glycosylation, movement through the Golgi system, and transport to lysosomes by an N-linked carbohydrate-independent mechanism of three lysosomal integral membrane proteins. J. Biol. Chem. 261, 16755-16763

46 Honing, S., Sandoval, I. V. and von Figura, K. (1998) A di-leucine-based motif in the cytoplasmic tail of LIMP-II and tyrosinase mediates selective binding of AP-3. EMBO J. 17, 13041314

47 Miedel, M. T., Weixel, K. M., Bruns, J. R., Traub, L. M. and Weisz, O. A. (2006) Posttranslational cleavage and adaptor protein complex-dependent trafficking of mucolipin-1. J. Biol. Chem. 281, 12751-12759

48 Niwa, K., Tanaka, R., Murase, H., Ishikawa, T., Fujita, H., Himeno, M. and Tanaka, Y. (2003) Two lysosomal membrane proteins, LGP85 and LGP107, are delivered to late endosomes/lysosomes through different intracellular routes after exiting from the trans-Golgi network. Biochem. Biophys. Res. Commun. 301, 833-840

49 Rodionov, D. G., Honing, S., Silye, A., Kongsvik, T. L., von Figura, K. and Bakke, O. (2002) Structural requirements for interactions between leucine-sorting signals and clathrin-associated adaptor protein complex AP3. J. Biol. Chem. 277, 47436-47443

50 Sandoval, I. V., Martinez-Arca, S., Valdueza, J., Palacios, S. and Holman, G. D. (2000) Distinct reading of different structural determinants modulates the dileucine-mediated transport steps of the lysosomal membrane protein LIMPII and the insulin-sensitive glucose transporter GLUT4. J. Biol. Chem. 275, 39874-39885

51 Traub, L. M. and Kornfeld, S. (1997) The trans-Golgi network: a late secretory sorting station. Curr. Opin. Cell Biol. 9, 527-533

52 Rohrer, J., Schweizer, A., Russell, D. and Kornfeld, S. (1996) The targeting of Lamp1 to lysosomes is dependent on the spacing of its cytoplasmic tail tyrosine sorting motif relative to the membrane. J. Cell Biol. 132, 565-576

53 Bernar, J., Tietze, F., Kohn, L. D., Bernardini, I., Harper, G. S., Grollman, E. F. and Gahl, W. A. (1986) Characteristics of a lysosomal membrane transport system for tyrosine and other neutral amino acids in rat thyroid cells. J. Biol. Chem. 261, 17107-17112

54 Jonas, A. J. (1986) Studies of lysosomal sialic acid metabolism: retention of sialic acid by Salla disease lysosomes. Biochem. Biophys. Res. Commun. 137, 175-181

55 Pisoni, R. L. and Thoene, J. G. (1989) Detection and characterization of a nucleoside transport system in human fibroblast lysosomes. J. Biol. Chem. 264, 4850-4856

56 Sagné, C., Agulhon, C., Ravassard, P., Darmon, M., Hamon, M., El Mestikawy, S., Gasnier, B. and Giros, B. (2001) Identification and characterization of a lysosomal transporter for small neutral amino acids. Proc. Natl. Acad. Sci. USA. 98, 7206-7211

57 Jonas, A. J., Smith, M. L. and Schneider, J. A. (1982) ATP-dependent lysosomal cystine efflux is defective in cystinosis. J. Biol. Chem. 257, 13185-13188

58 Renlund, M., Tietze, F. and Gahl, W. A. (1986) Defective sialic acid egress from isolated fibroblast lysosomes of patients with Salla disease. Science. 232, 759-762

59 Tietze, F., Seppala, R., Renlund, M., Hopwood, J. J., Harper, G. S., Thomas, G. H. and Gahl, W. A. (1989) Defective lysosomal egress of free sialic acid (N-acetylneuraminic acid) in fibroblasts of patients with infantile free sialic acid storage disease. J. Biol. Chem. 264, 15316-15322

60 Kalatzis, V., Cherqui, S., Antignac, C. and Gasnier, B. (2001) Cystinosin, the protein defective in cystinosis, is a $\mathrm{H}(+)$-driven lysosomal cystine transporter. EMBO J. 20, 5940-5949 


\section{FIGURES LEGENDS}

Figure 1. Mutation of the putative sorting motifs of p40. p40 is a protein of 372 amino acids containing 4 potential lysosomal membrane targeting signals. Three are of the YXX $\phi$-type $\left(\mathrm{Y}^{6} \mathrm{QLF}\right.$, $\left.\mathrm{Y}^{106} \mathrm{VAL}, \mathrm{Y}^{333} \mathrm{NGL}\right)$ and one of the dileucine-type (EQERL ${ }^{360} \mathrm{~L}^{361}$ ). Mutational analysis of these motifs was performed as described in Material and Methods. Tyrosine residues at positions 6, 106 or 333 were replaced by alanine. The two leucine residues situated 11 and 12 residues upstream from the Cterminal end $\left(\mathrm{L}^{360} \mathrm{~L}^{361}\right)$ were replaced by an alanine and a valine, respectively.

Figure 2. Role of the tyrosine motifs in the subcellular sorting of p40. A. HeLa cells transiently transfected with $\mathrm{p} 40$ proteins (p40, p40-GFP, $\mathrm{p} 40$-HA or GFP-p40) were fixed $48 \mathrm{~h}$ post-transfection, permeabilised, and incubated with an anti-LAMP-1 antibody followed by an Alexa 568-conjugated goat anti-mouse secondary antibody (red). Cells transfected with wild-type $\mathrm{p} 40$ were incubated with a polyclonal rabbit antibody raised against the last 15 amino acids of the protein, followed by an Alexa 488-conjugated anti-rabbit antibody (green). Similarly, HA-fused proteins were detected with an antiHA specific polyclonal rabbit antibody followed by the Alexa 488-conjugated anti-rabbit antibody (green). The fluorescent signals of the GFP and of secondary antibodies were observed by confocal fluorescence microscopy. B. HeLa cells transfected with p40-GFP constructs bearing the mutation of one tyrosine motif (Y6A, Y106A or Y333A) were subjected to a LAMP-1 detection as described in A.

Figure 3. Intracellular distribution of the $\mathbf{p 4 0}$ proteins mutated in the C-terminal dileucine motif. A. HeLa cells were transiently transfected with $\mathrm{p} 40$ or $\mathrm{p} 40$ fusion proteins (p40-GFP, GFP-p40 or p40$\mathrm{HA})$ in which the two leucine residues $\left(\mathrm{L}^{360} \mathrm{~L}^{361}\right)$ were replaced by an alanine and a valine, respectively. $48 \mathrm{~h}$ post-transfection, cells were fixed and LAMP-1, p40 and p40-HA were detected by confocal microscopy with specific antibodies as described in figure 2 . B. $48 \mathrm{~h}$ post-transfection, HeLa cells expressing p40-GFP or p40-LL360AV-GFP (dileucine mutant) were pulsed for 6 hours with 2 $\mathrm{mg} / \mathrm{ml}$ Texas Red-dextran, followed by $2 \mathrm{~h}$ chase in a dextran-free medium. Cells were fixed and observed with a confocal fluorescence microscope.

Figure 4. Combined mutation of the tyrosine and dileucine motifs in p40-GFP. 48 h post-transfection with p40-GFP proteins harboring at least the dileucine substitution, combined to the mutation of one (double mutants: Y6A, Y106A or Y333A + LL360AV), or of the three tyrosine motifs (quadruple mutant: Y6A-Y106A-Y333A-LL360AV), cells were fixed and LAMP-1 was detected as described in figure 2 .

Figure 5. Analysis of the subcellular distribution of 40 and p40-GFP dileucine mutants, by fractionation on self-forming Percoll density gradients. HeLa cells were transfected with $\mathrm{p} 40$, p40GFP, p40 with the dileucine mutation (p40-LL360AV) or the dileucine mutant of p40-GFP (p40LL360AV-GFP). $48 \mathrm{~h}$ later, MLP fractions were prepared and fractionated on self-forming Percoll density gradients as described in Material and Methods. Seven fractions were collected and enzymatic activities of $\beta$-galactosidase ( $)$ and alkaline phosphodiesterase ( $\square$ ) were measured to localise the lysosomes and the plasma membrane, respectively. Values on the graph represents the average percentage (+/- SD) of the enzymatic activity in each of the 7 fractions, calculated from all the experiments performed $(n=12)$. The open circles $(O)$ represent the density of Percoll. The distributions of the late endosomal/lysosomal marker LAMP-1 and of the p40 proteins were analysed by Western blotting. Blots correspond to one representative experiment.

Figure 6. Relative abundance of the p40 constructs at the plasma membrane in HeLa cells. A. $48 \mathrm{~h}$ post-transfection with p40-GFP constructs, HeLa cells were incubated on ice with a biotinylation reagent (Sulfo-NHS-S-S-Biotin), as described in Material and Methods. Biotinylated (Bound, B) proteins were separated from non-biotinylated ones (Unbound, $U$ ) by absorption on streptavidine agarose beads. Biotinylated proteins and one tenth of the non-biotinylated fraction were resolved by SDS-PAGE and the p40 proteins were detected by ECL-Plex ${ }^{\text {TM }}$ Western blotting. Signals were quantified with the ImageQuant ${ }^{\mathrm{TM}}$ Software and the abundance of the biotinylated fraction relative to the total p40 proteins (Bound + Unbound signals) was calculated. Graph represents average values +/- 
$\mathrm{SD}$, with $\mathrm{n} \geq 3$. EEA1 was used as a negative control. B. HeLa cells transfected with the wild-type or the dileucine mutated forms (LL360AV) of p40, p40-HA or GFP-p40 were subjected to the cell surface biotinylation assay. Proteins were detected among the biotinylated and non-biotinylated fractions $\left(1 / 10^{\text {th }}\right)$ by Western blotting. Values on the histograms represent the percentage of the biotinylated signal relative to the total amount of $\mathrm{p} 40$ proteins (average $+/-\mathrm{SD}, \mathrm{n} \geq 3$ ).

Figure 7. Intracellular trafficking of p40 constructs. A. HeLa cells transiently transfected with a dominant negative construct of Eps15 tagged with GFP (GFP-E $495 / 295)$ were incubated $24 \mathrm{~h}$ posttransfection with Alexa 568-conjugated transferrin for $15 \mathrm{~min}$ at $37^{\circ} \mathrm{C}$. After fixation with $4 \%$ paraformaldehyde and mounting in Mowiol, cells were observed by confocal fluorescent microscopy. B-C. HeLa cells were transiently cotransfected with a plasmid containing either wild-type-p40-HA (B) or p40-LL360AV-HA (C) together with the GFP-EA95/295 construct. Twenty-four hours posttransfection, cells were fixed, permeabilised, and incubated with an anti-HA rabbit antibody followed by an Alexa 568-conjugated anti-rabbit secondary antibody. Arrows point to cells expressing GFPE $\Delta 95 / 295$ in which the uptake of transferrin was efficiently inhibited. 
Figure 1

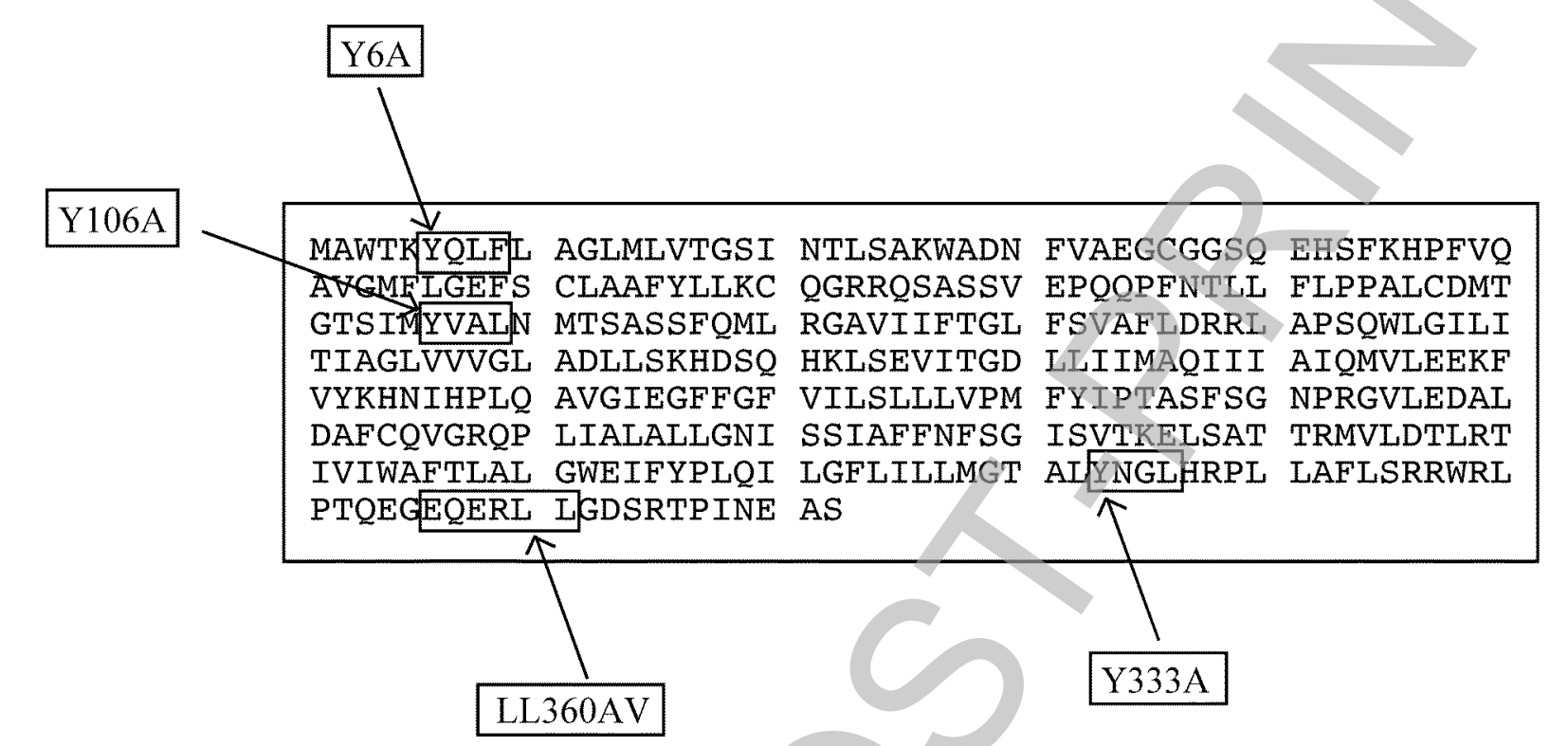


Figure 2A

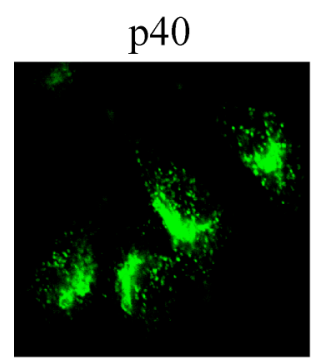

LAMP-1

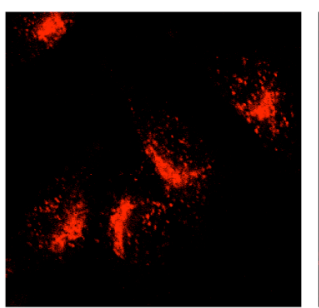

Overlay
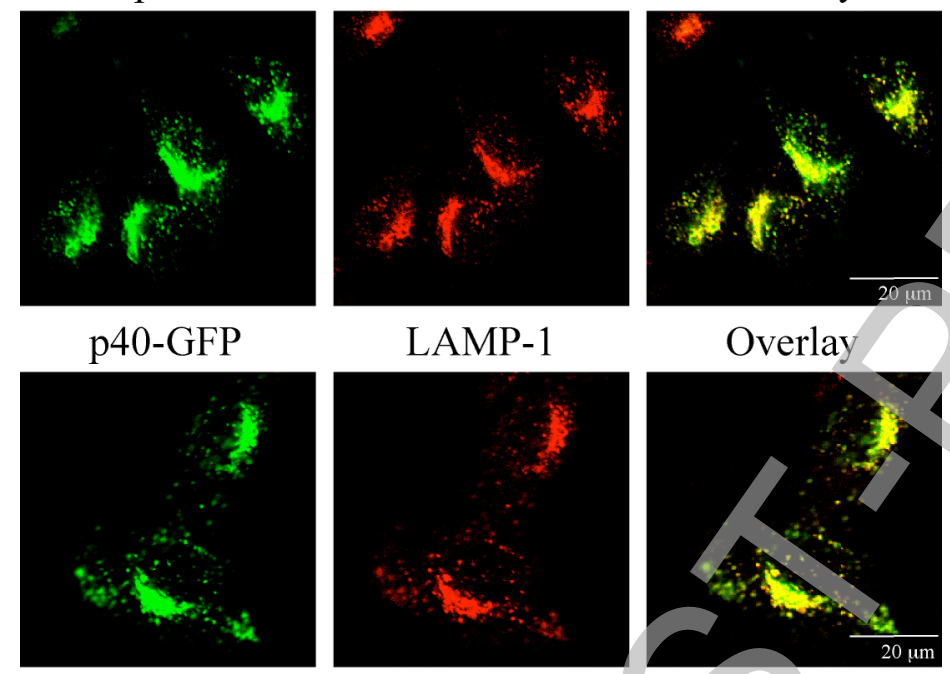

LAMP-1

Overlay
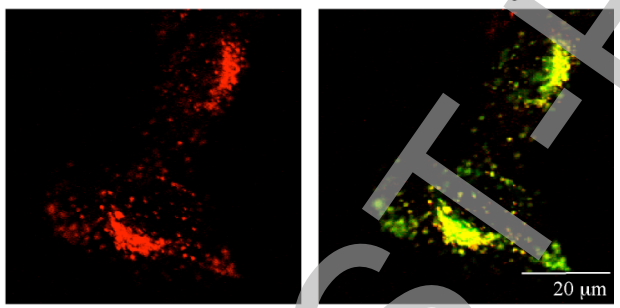

GFP-p40

LAMP-1

Overlay
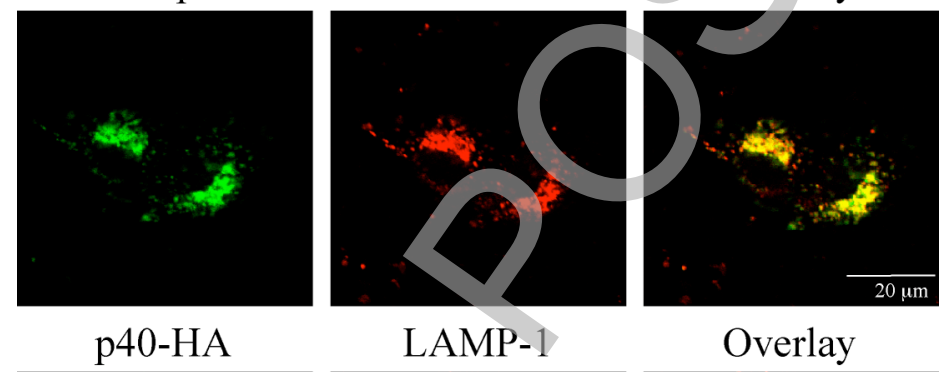

LAMP-1

Overlay
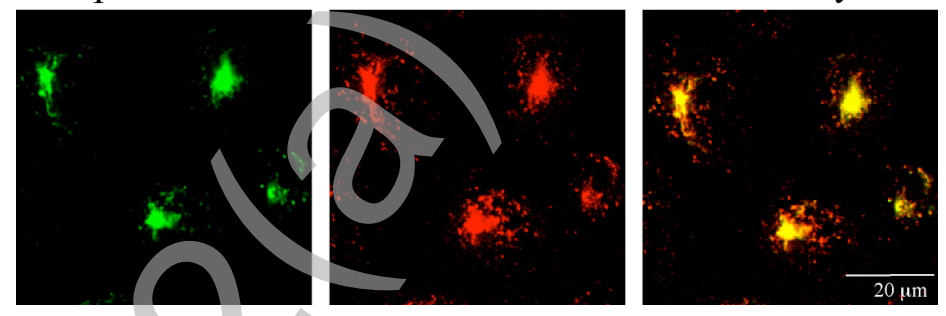
Figure 2B

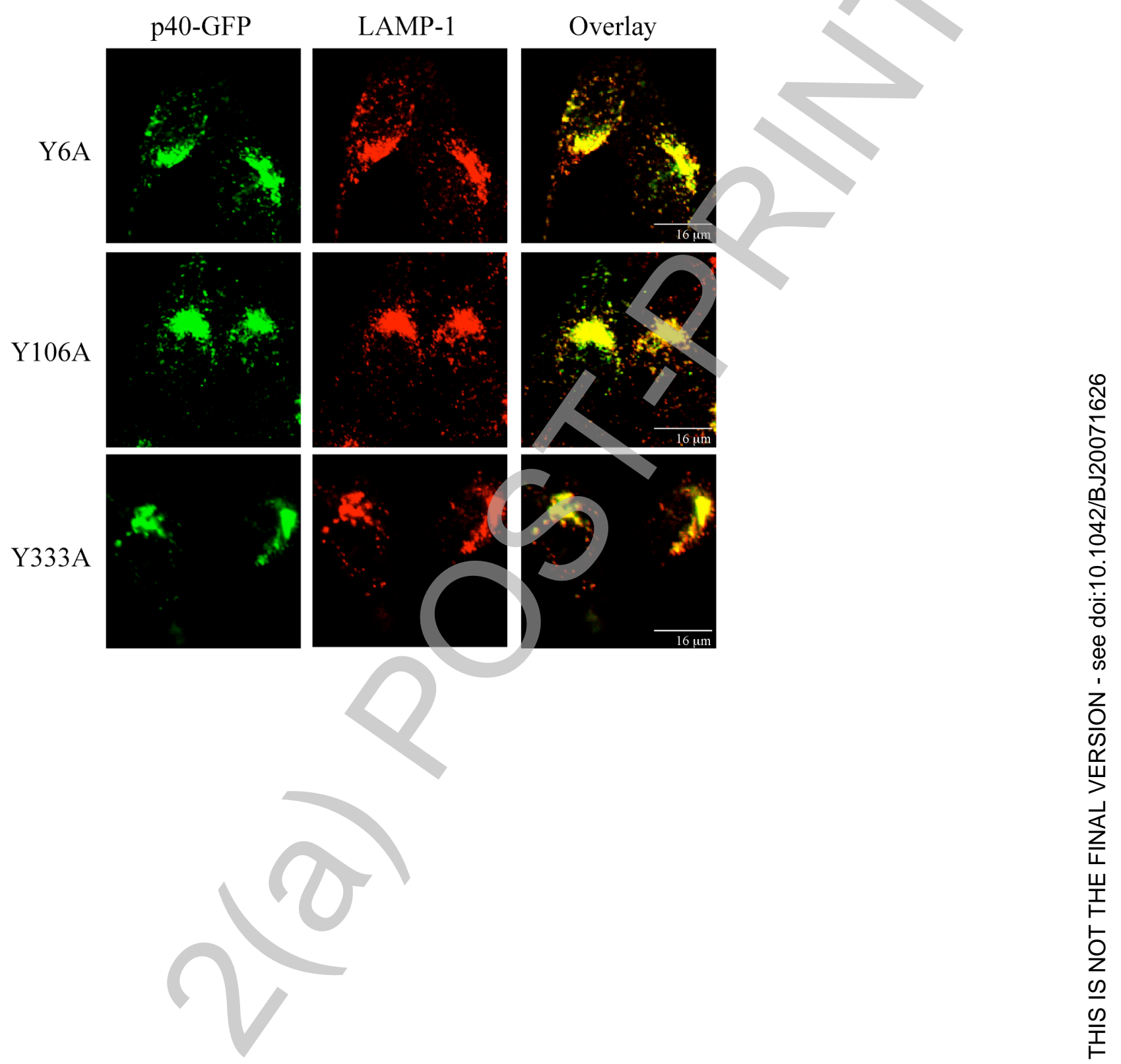


Biochemical Journal Immediate Publication. Published on 14 May 2008 as manuscript BJ20071626

Figure 3A

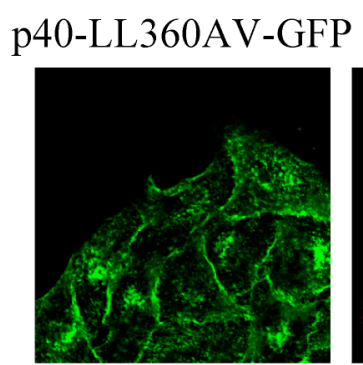

LAMP-1

Overlay
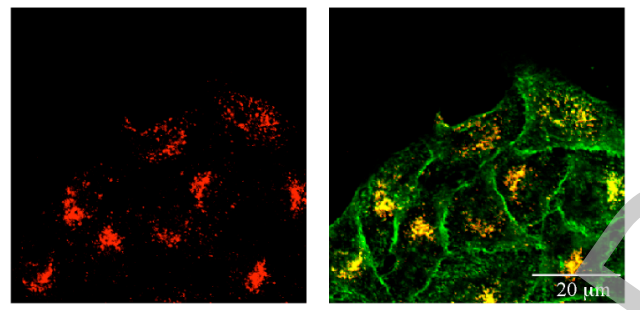

p40-LL360AV

LAMP-1

Overlay
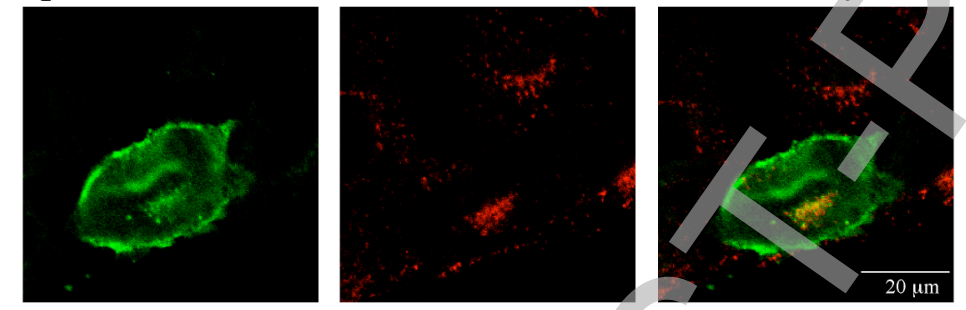

GFP-p40-LL360AV

LAMP-1

Overlay
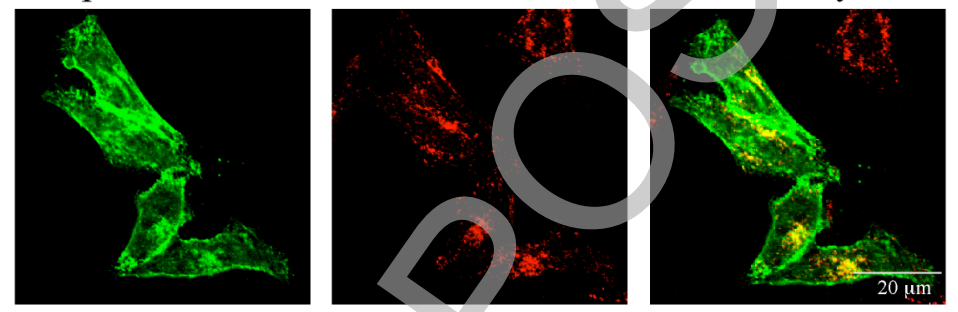

p40-LL360AV-HA

LAMP-1

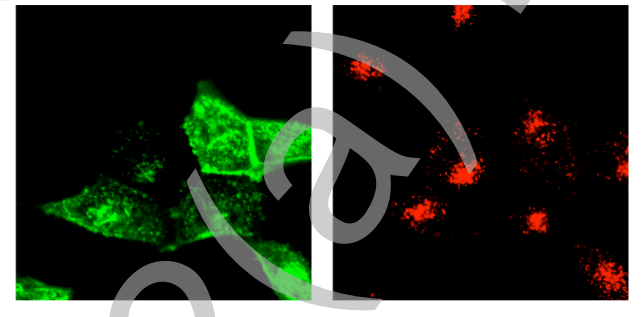

Overlay

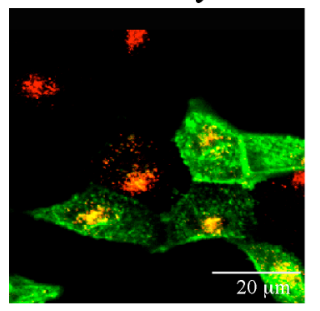


Figure 3B

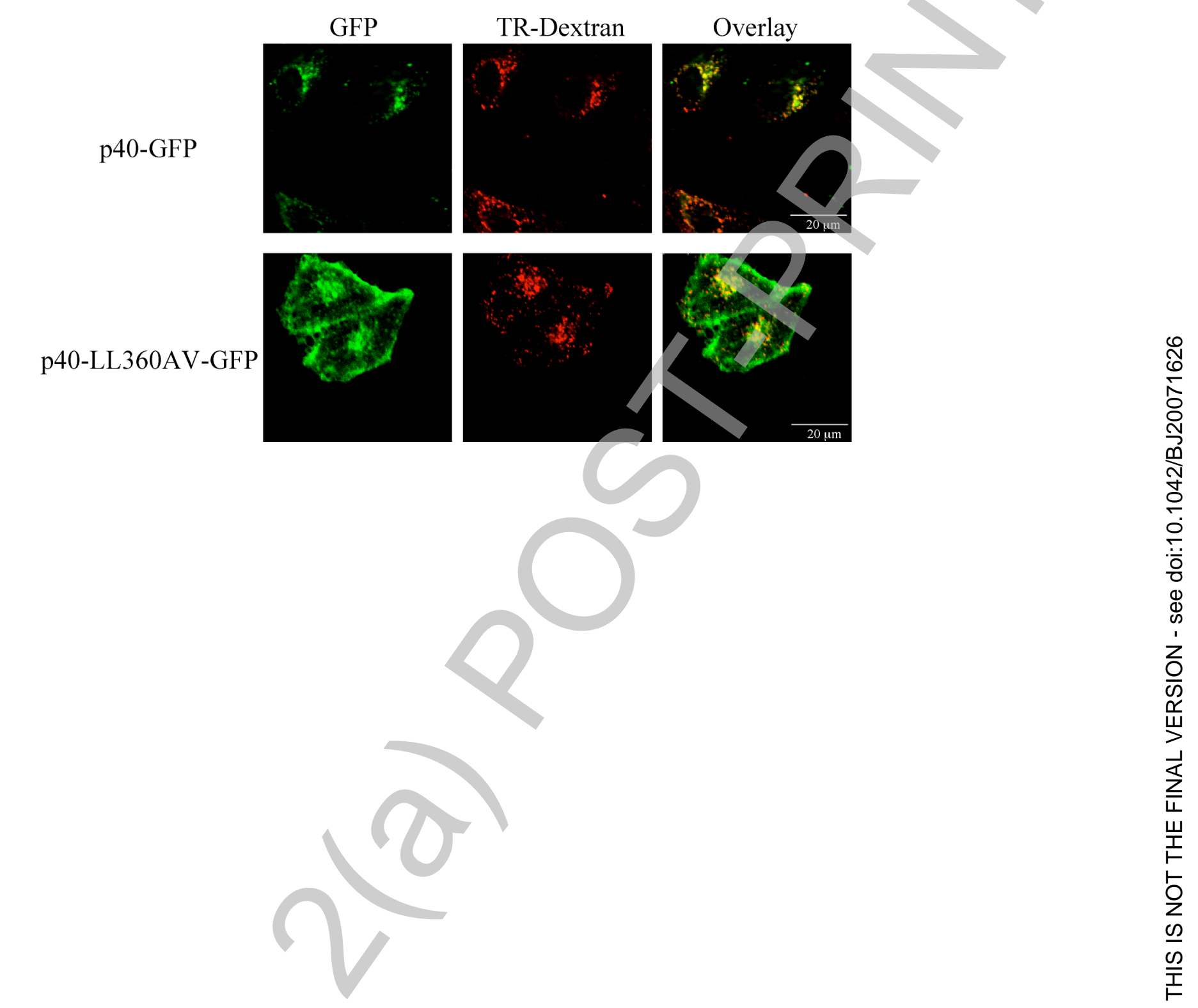


Figure 4

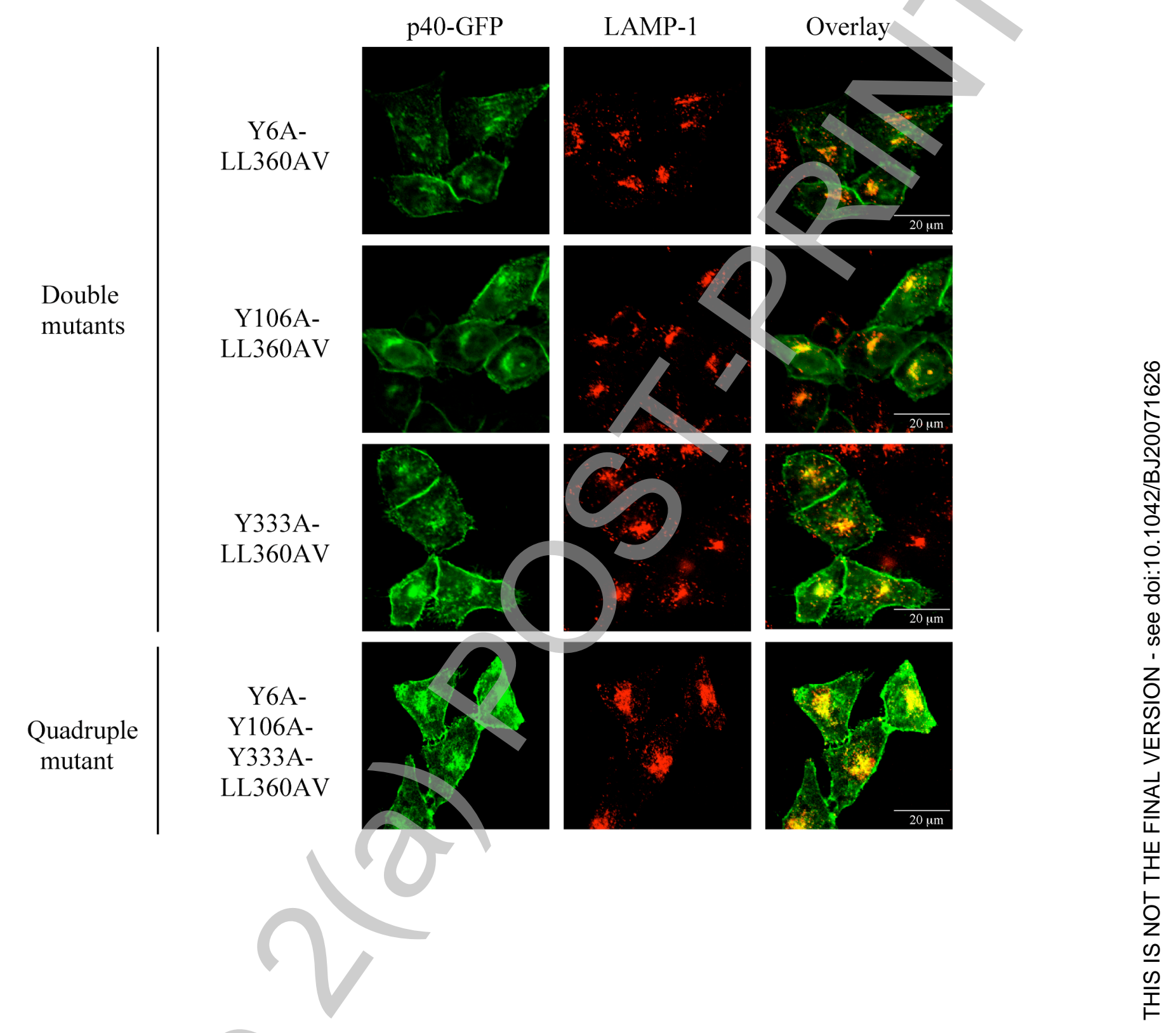


Figure 5
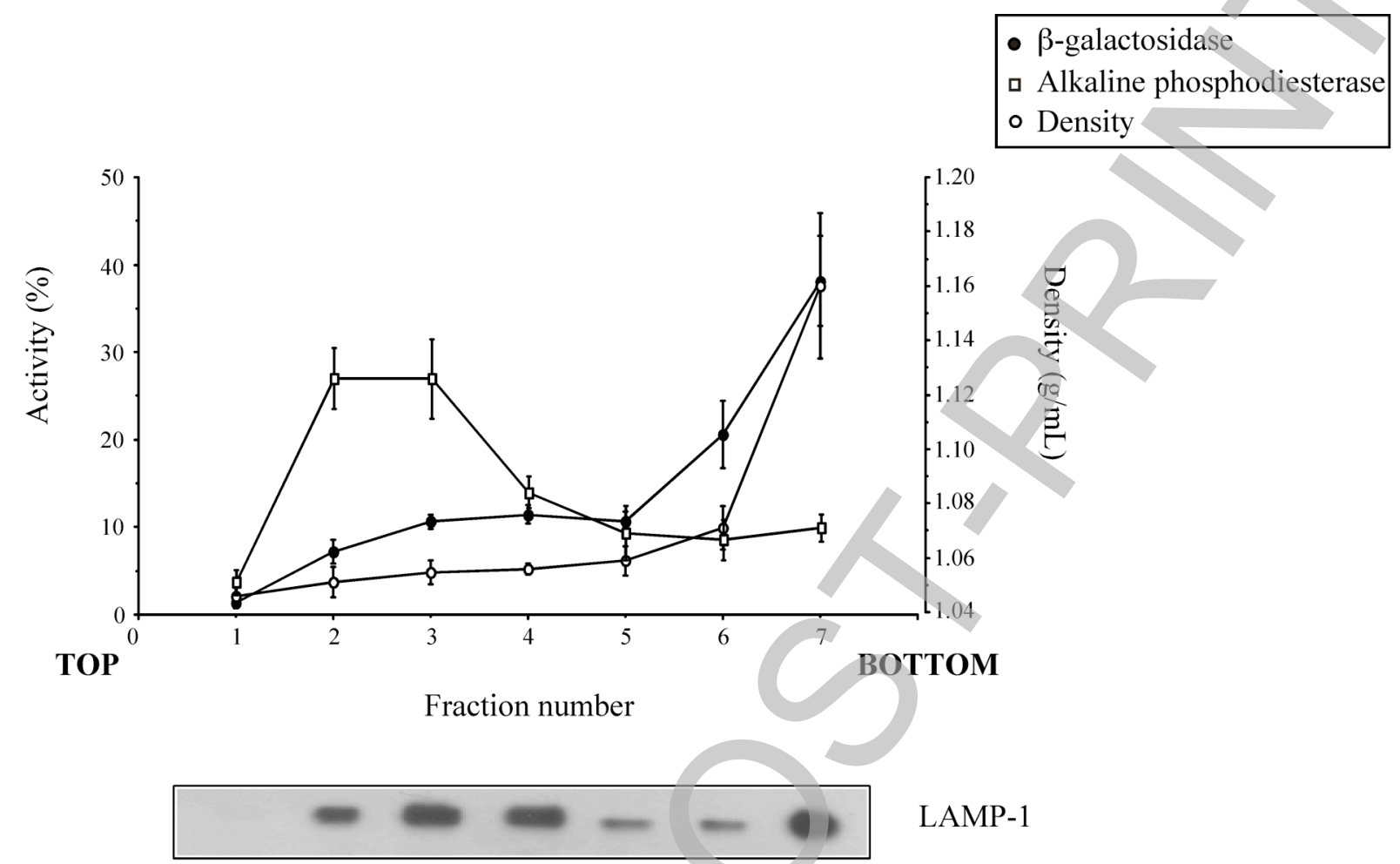

LAMP-1

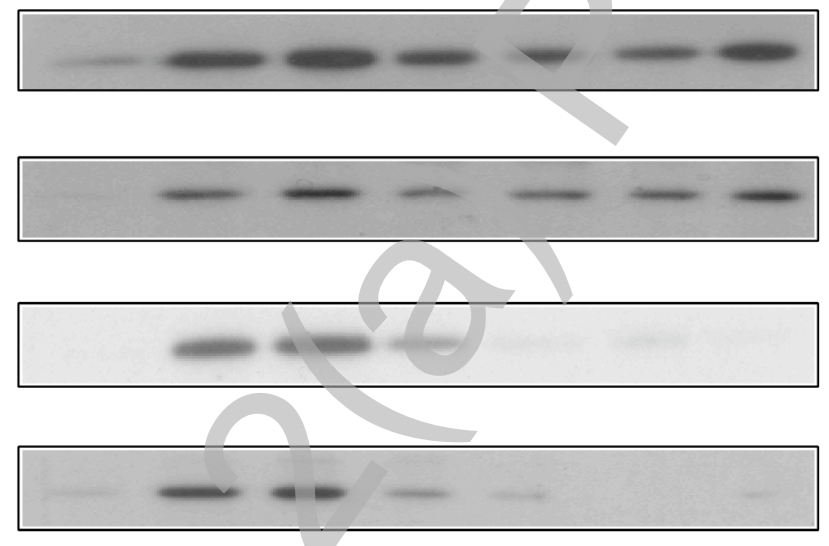

p40

p40-GFP

p40-LL360AV

p40-LL360AV-GFP 
Figure 6A

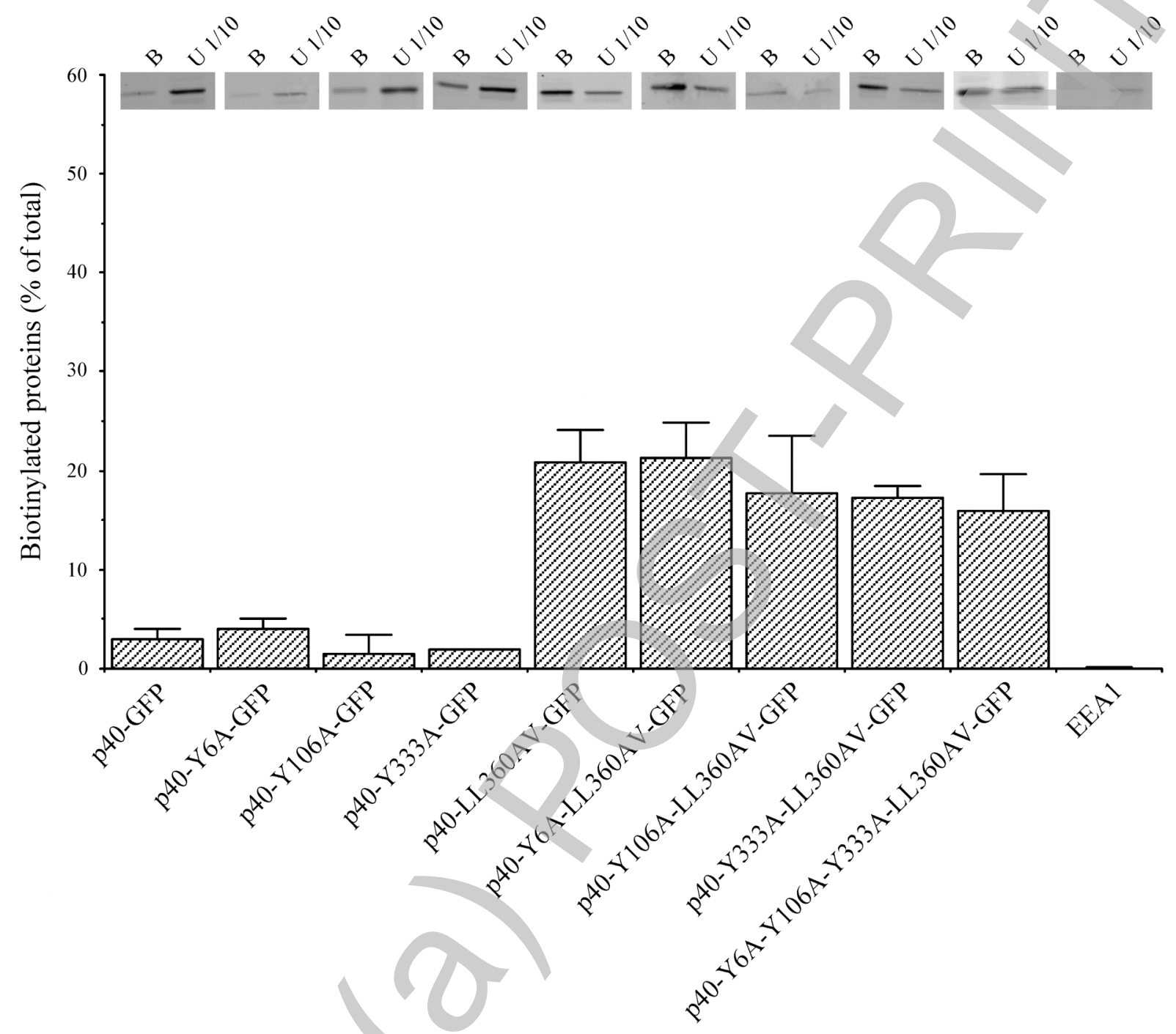


Figure 6B

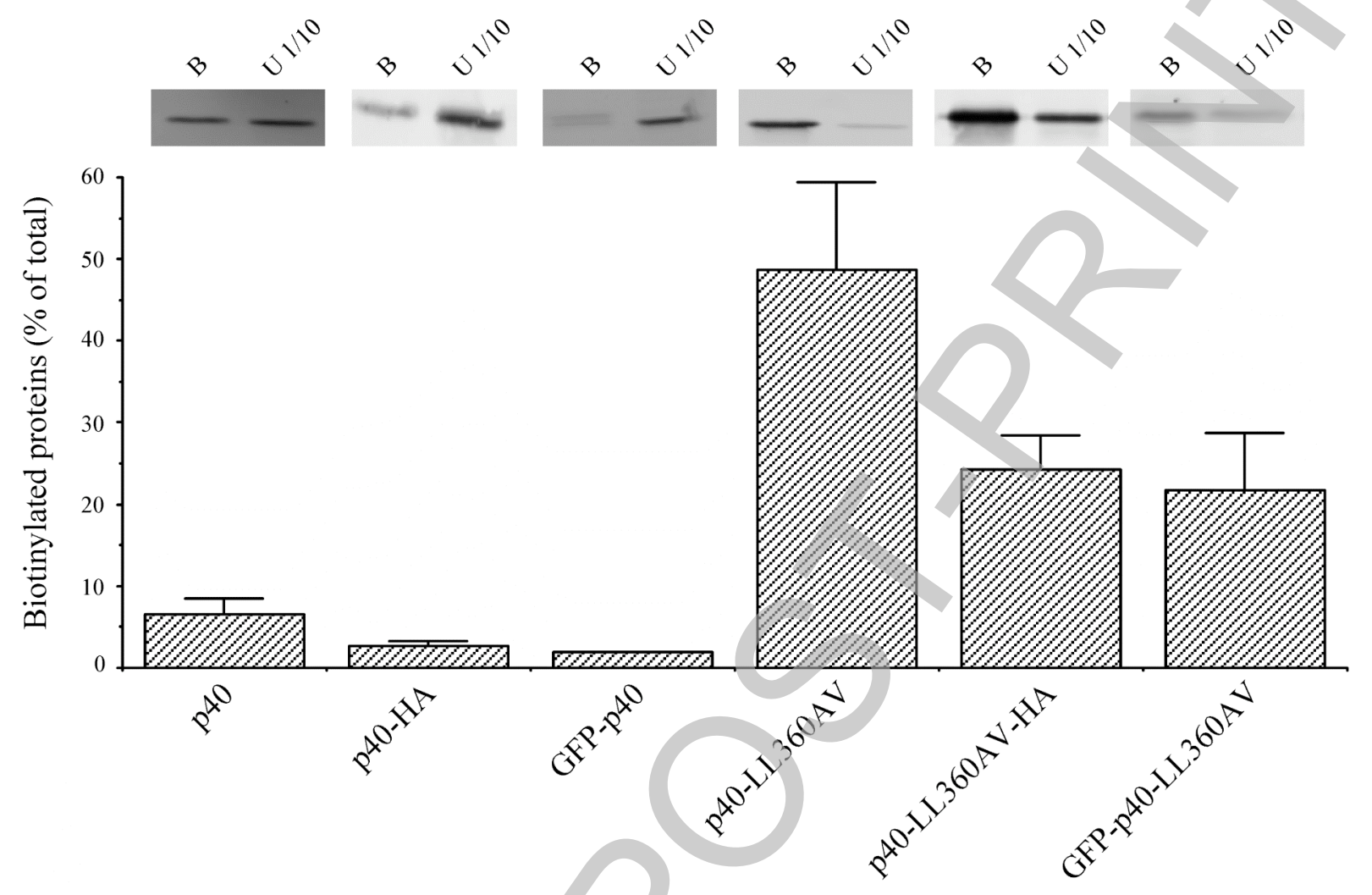


Figure 7

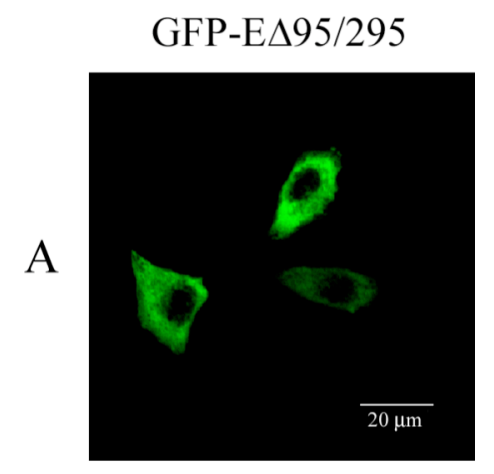

Alexa-568-Transferrin
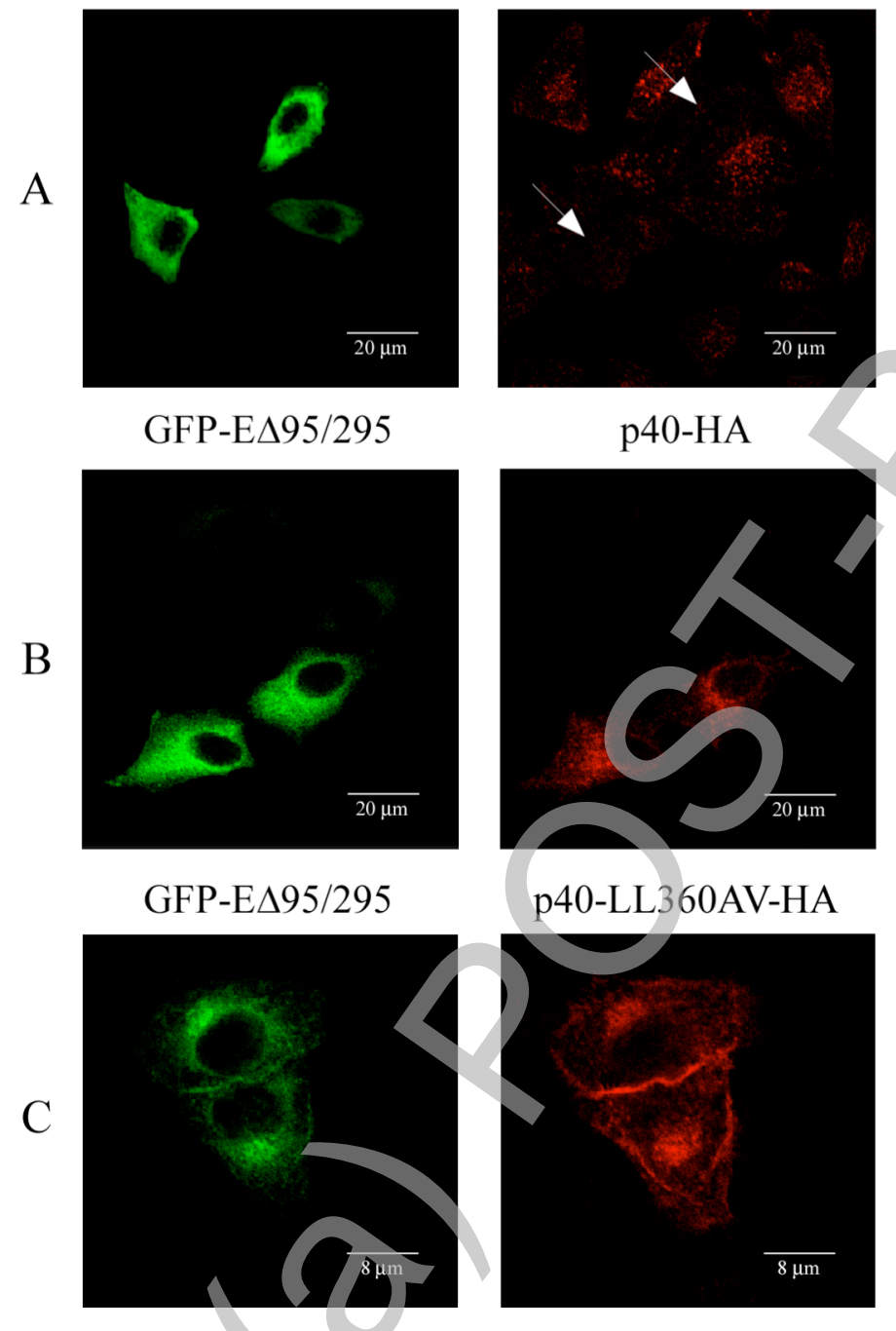

Licenced copy. Copying is not permitted, except with prior permission and as allowed by law. (C) 2008 The Authors Journal compilation (C) 2008 Biochemical Society 